\title{
Coping Strategies of Newcomers Quick Departure in the Early Entry: Expectation and Organization Support's Effect_—on Perspective of Organizational Socialization
}

\author{
Yanjuan $\mathrm{MO}^{1, \mathrm{a}}$, Wei $\mathrm{LI}^{2, \mathrm{~b}}$ \\ ${ }^{1}$ Business school of Sichuan University, No.24, A Loop for A Period of South, Wuhou District, \\ Chengdu, PO Box 610065, China \\ ${ }^{2}$ Business school of Sichuan University, No.24, A Loop for A Period of South, Wuhou District, \\ Chengdu, PO Box 610065, China \\ amajorjiayou@163.com, ${ }^{\text {b }}$ liweilzy@scu.edu.cn
}

Keywords: Newcomers; Quick Departure; Organizational Socialization; Expectation; Organizational Support.

\begin{abstract}
Quick departure of newcomers in first year is "never good" to organization. The impact of organizational socialization tactics on retention of newcomers is very important. The article explored reasons of newcomers quick departure from the perspective of organizational socialization, we propose that personal factors of met expectation and contextual factors of organization support have particular important effects on newcomers organizational socialization in the early entry, thus lead to quick departure. According to the analyzed reasons of newcomers' quick departure, we propose reasonable socialization tactics to prevent and reduce newcomers' quick departure.
\end{abstract}

\section{Introduction}

Departure refers to "the process that individuals who get material profits from the organization terminate the relationship with organization" [1]. Newcomers' departure in early period refers to newcomers who joint into the organization less than a year take termination of material benefits with organizations on the basis of just understand organization and grasp the work. This just recruited in happened departure soon is a big loss for enterprise because the recruitment, training, and replacement costs are very high. Scholars researched on departure in early age paid more attention to mental models, influence factors and the cost of office. However they didn't analysis the causes of departure in different stages. Departure could happen in the early entry, professional development period, career peak period and stability period and has its specific characteristics of organization factors and individual factors in different period. So it's necessary to discuss causes and strategies in stages. Organizational socialization tactics for newcomers' retention have a very important role because departure rate in first year of employee orientation usually highest and dysfunctional [2]. So, this article explores reasons for newcomers quickly leaving, argues that personal factors of newcomers' expectation and situational factors of organizational support have a direct impact for their organizational socialization, and influence quick departure.

\section{Organizational Socialization and Newcomers Quick Departure in the early entry}

Newcomers characteristics in the early entry: (1) held expectations of organization before the entry and remain relatively stable after induction; (2) corresponding roles of social or group in new field will be changed with their entry from a field into another new field [3]; (3) perceive the impact of personal expectations with enterprise reality and the uncertainty and anxiety brought by strangeness of new environment and character. Because of such characteristics, organizations may take several socialization strategies like organized training, specified guiding teacher, organized induction 
ceremony to ease their psychological discomfort, master work as soon as possible and integrate into the new environment. In the process of organizational socialization, some researchers emphasized the interaction in the early entry have a far-reaching impact on later work like work mastering, performance, termination and so on [4]. Clearly, organizational socialization tactics are particularly critical for new hires which lack of understanding and interaction of organization during early entry.

Feldman held view that organizational socialization is the process of external personnel turned into internal staff of participatory and efficiency [5]. Organizational socialization affects perceived personal - organization of staff and values match level and these may affect departure by cognitive [6]. Numerous studies have made it clear that newcomers' organizational socialization will affect their future departure behavior [7]. There is no doubt organizational socialization has the impact of departure behavior. Organizational socialization results are divided into proximal and distal result, and researches suggest that the proximal result is directly related to organizational socialization content, distal result is the further result of proximal and influenced by other factors [8]. Although quick departure is the distal result of organizational socialization during early entry, it closely related with the proximal results and influenced in direct due to the particularity of its time. The proximal result was qualified for task master, roles clear, organization understanding and social integration according to prevailing view in research of organizational socialization [9]. Task master refers to evaluate their ability to complete job successfully; role clear refers to understand organization and job expectations of their actions; social integration refers to form a personal relationship with colleagues and embodied in the work group; organization understanding refers to the degree that members understand and grasp informal power network and interpersonal network in organization.

Based on the characteristics of newcomers' early entry period, newcomers' expectation and social environment will have a direct role to their adaption during early entry which affects its organizational socialization. Newcomers expect will affect subsequent adaptation, they will need support from organization members to help the organization adapting and relationships building in condition of new environment and new role. We could see, newcomers expect and organizational support produce direct and significant effect to the proximal results of organizational socialization, in turns it will affect the departure.

\section{Newcomers Expect and Organizational Support Effect on Organizational Socialization}

The Role of Newcomers Expect. Newcomers expect is an important psychological variable in organizational socialization process, which has been formed before entering the organization based on the information and relevant experience [4]. Some scholars pointed out that job expectation effect on employees' subjective attitude towards to work and subjective attitude affects departure or intention of stay [10]. Newcomers' subjective attitude expressed by behavior and mainly performed on understanding of new role and master of task, which is task mastery and role clear in the socialization process.

According to role identity theory, "role" represents the common expectations that people have about bear social identity, and the meaning given by different roles in society formed "self -concept". Self-concept is a clear understanding of own identity under different environment and clearly know their identity concept. Employees need to understand the significance of self-concept in social interaction to guide their behavior in social contacts. "Role identity" will facilitate task master for they have effective self-evaluation on completion of successfully complete the role responsibilities.

Different expectations may have opposite effects on organizational socialization. Studies have shown that the lower expectations, the better adaptation [11], while others argued that the higher expectations, the better adaptation [12]. The key problem is expectations were met or not be implemented but not held high expectations or low expectations in the early. Met expectations were correlated with self-efficacy, job performance and motivation [4]. And not met expectations will form 
expectation gap, means "the difference between positive or negative experience in working and expect experience" [13], and it will damage organization socialization. Specifically, expectation gap will appear when larger mismatch appeared between expectations and the enterprise reality. This kind of expectation gap brought great psychological impact to new staff which was in a new environment and uncertainty. It will bring newcomers negative emotional experience, lower job role understanding and enthusiasm of studying work skills. Thereby directly affect organizational socialization smoothly and lead to absenteeism and turnover because of unsatisfied.

In particular, when expectation met with enterprise reality, newcomers inner expectations are met, thus reduce insecurity and uncertainty. They will be more objective and optimistic on self role cognition, more actively looking for job skills and learning task and easy for promote organizational socialization. Expectation gap was formed when newcomers' expectation and organizational reality appear a larger mismatched and newcomers show no identity and unsatisfied to enterprise reality along with anxiety and uncertainty caused by new environment. This kind of no identity influence work and character which employee first contact. In new environment, newcomers need to know their identity clearly and show corresponding behavior according to their own cognitive. And in the situation of expectation gap, anxiety and uncertainty which brought by gap may blow newcomers enthusiasm of active self-role cognition, lead to cannot understand role or couldn't even show identity role, which hinder the social. The model of Steers and Mowday points out that expect affect employee subjective attitude towards work [10]. The generation of expectation gap hit new staff's enthusiasm about self-role cognition and work. So newcomers can't afford the corresponding role through the clarity description of the role and character recognition in work tasks, also can't learn and master skills of successful completion of the role. There will be vicious circles in the subsequent work like “expectation gap--role no identity -- not active--ability can't be improved--task can't be mastered--gap expanded-- role no identity......" Such a vicious circle, finally makes them feel a strong sense of not satisfied. Turnover intention produced due to job dissatisfaction and then began to look for alternative work, at last resulting in quick departure. Obviously, newcomers expect effect on proximal results of organizational socialization which are role clarity and task master, thus affect quick departure in early.

The role of organizational support . Support from existing staff can help news quickly adapt, and undermining from existing staff will make their socialization process and organization adaption to be difficult. Indeed, newcomers have the need of social support in this special time. Organizational socialization is a process to adapt to the organizational culture and integrated into the organization. People not only take on certain roles and also a member of groups in society [3]. Social identity theory takes "community" as the research unit, describe several people formed a group on the basis of some shared characteristics, and these common characteristics are different from other groups, so distinguish their group with other groups. This positive distinguish of self-group concept comes from social identity. Precondition to be the member of the organization is to understand and agree with the corresponding organization common trait of groups, namely build social identity. Social identity mainly build was embodied in understanding of organization and social integration during organizational socialization. Some scholars pointed out that socialization process experienced by group member is the process of cognitive which people understand corresponding social identity through constantly social interaction [14].

It's a problem to create conditions for promoting socialization smoothly of newcomers to understand and integrate into organization. Studies have shown that support from supervisor and colleagues have a direct impact for newcomers' attitude and behavior, and this effect has already begun in the early [14]. Support from superiors will bring psychological comfort feeling which help for alleviate initial tension and uneasiness; support from colleagues will reduce some of the impact from new environment and reduce helplessness that staff facing on new environment and new faces. These organizational supports could effectively promote their social integration and organization understanding, to help newcomer from outside people into insider. 
Specifically, when newcomers enter into a new organization feel the friendly welcome and emotional support from members of the organization, especially his supervisors and colleagues, they will be more active to understand organization, and more willing to into the organization. The support from organization makes newcomers perceive the willing that organization regarding them as tissue insiders. AS a situation of insecurity, newcomers would like to define themselves as insiders and subsumed themselves in the class of organization members. Under the self-concept of groups' insider, newcomers will be active to understand members in organization, deep understanding of organizational culture, and guide their behaviors, making oneself showed the same characteristics as members in organization. For these common characteristics different from other groups, thus distinguish this group and other groups, shows organization understanding and identity. In group interaction, personal self-concept was defined by Social identity on the basis of group characteristics, people feel themselves embodies more are characteristics of subordinate to the group rather than personal traits, that is produce a concept of "who we are". It's help for promoting newcomers friendship between superiors and colleagues stretching out their hands to help in special period, the building of informal relationship and construction of auxiliary formal relationship could assist the construction of formal relationship, thus newcomers can be integrated into organization better, to be a real organization insider.

However, if colleagues and superiors show not support when newcomers into the company, their insecurity and anxiety will be strengthen, thus have a bad impression. Newcomers feel sense of isolation in absence of positive organizational support. Feeling exclusive sense newcomers may choose enterprise in outside groups in society classified, not too objective organizations understanding and think more about negative traits. In addition, because lack of organizational support, they tend to distinguish themselves and organization when carries on self-concept definition, shows low commitment and social identity. Mutation "rush" model of Sheridan and Abelson pointed out that newcomers will jump to surface of departure when organizational commitment declined continuously [15]. Not supporting from members has a negative effect on organizational socialization and be obstacles to embed. Allen proposed a social strategy for mechanism of departure, pointed out that socialization effort is to make the new staff more widely embedded in the organization, enter a network which connected with organization, thus reduce departure [2]. Newcomers will give up and resulting in quick departure in the case of can't be in a group.

\section{Socialization Tactics of Newcomers Quick Departure}

We could see the key reasons of hasty departure were the formation of expectation gap and lack of organizational support. Organizations should pay attention to newcomers' early expectations and expectations after entry to take corresponding strategies.

Public true information and adopt realistic job preview, lowering expectations. Newcomers tend to form high expectations before entering as companies like to exaggerate its advantages in recruitment and reasons like job seekers inherent attribution bias. In order to minimize the expectation gap, enterprise should promote real information when recruiting propaganda. In addition, they can give workers more actual information about business and work through realistic job preview. Real information find suitable person truly, significantly reduce departure.

Take psychological evaluation to understand employee expectations, select suitable employees. Take psychological evaluation after newcomers knew enterprise information, inspecting their expectations are reality or formed higher expectations, taking proper selection and asking about their expectations of enterprise. Through that, screen employees suitable for enterprise culture; reflect the real situation through question and feedback, low down their expectation to reduce rapid turnover.

Pre-service training and group activities before working, create a relaxed welcome atmosphere, promoting social integration. Pre-service training and group activities before working 
can reduce role of fuzzy for newcomers and insecurity of not clear job content. Arrange some group activities for news can ease their anxiety and uncertainty. Newcomers will have information sharing and interaction partners in works because of informal membership. Group activities reduce insecurity and enhance team cohesion, promote their socialization, thus reduce quick departure.

Carry out new and old staff exchanges, provide platform to build relationships, enhance organizational understanding. On the one hand, this method may help for build an informal relationship, promote newcomers familiar with and integrate into the enterprise faster. On the other hand, old employees can communicate with them on the experience, make it perceived themselves as insiders. There are a lot of new and old staff communication activities, the main purpose is to provide platform to build relationships and enhance organization understanding.

\section{Literature References}

[1] Mobley W H., Intermediate linkage in the relationship between job satisfaction and employee turnover. Journal of Applied Psychology, 1977, 62(2): 237-240.

[2] Allen,D.G., Do organizational socialization tactics influence newcomer embeddedness and turnover, Journal of Management, 2006, 32, 237 - 256.

[3] Stets, J, Identity theory, In P. J. Burke (Ed.), Contemporary Social Psychological Theories, 2006, pp.88-110, Stanford, California: Stanford Social Sciences.

[4] Wanous J P, Poland T D, Premack S L, et al, The effects of met expectations on newcomer attitudes and behaviors: a review and met-analysis, Journal of Applied Psychology, 1992, 77 (2) : 288-297.

[5] Feldman D C. A contingency theory of socialization [J], Administrative Science Quarterly, 1976: 433-452.

[6] Cable D M, Parsons C K. Socialization tactics and person - organization fit [J]. Personnel Psychology, 2001, 54(1): 1-23.

[7] Van Maanen J E, Schein E H, Toward a theory of organizational socialization, Research in Organizational Behavior [J], 1977, 209-264.

[8] Bauer T N, Bodner T, Tucker J S. Newcomer adjustment during organizational socialization: a meta-analytic review of antecedents, outcomes, and methods. Journal of Applied Psychology, 2007, 92 (3) : 707-721.

[9] Kammeyer-Mueller J D, Wanberg C R, Unwrapping the organizational entry process: disentangling multiple antecedents and their pathways to adjustment [J]. Journal of Applied Psychology, 2003, 88(5): 779.

[10] Steers R M, Mowday R T, Employee Turnover and Post-decision Accommodation Process. In: Cummings L L, Staw B M. ed, Research in Organizational Behavior. Greenwich, Conn.: JAI Press, 1981. 235-281.

[11] Buckley M R, Fedor D B, Veres J G, et al, Investigating newcomer expectations and job-related outcomes. Journal of Applied Psychology, 1998, 83: 452-462.

[12] Bell B S, Wiechmann D, Ryan A M., Consequences of organizational justice expectations in a selection system, Journal of Applied Psychology, 2004, 91 (2): 455-466.

[13] Porter L W,Steers R M., Organizational ,work ,and personal factors in employee turnover and absenteeism. Psychological Bulletin, 1973, 80 (2):151 - 176. 
[14] Yan Ming, Tu Hongwei, Li Ji, The definition of organizational socialization and identity perspective new staff structure dimension. Progress in Psychological Science, 2011, 19 (5), 624-632.

[15] John E. Sheridan and Michael A. Abelson, Cusp Catastrophe Model of Employee Turnover, The Academy of Management Journal, 1983, Vol. 26, No. 3, pp. 418-436. 